\title{
Neuropsin (KLK8)-Dependent and -Independent Synaptic Tagging in the Schaffer-Collateral Pathway of Mouse Hippocampus
}

\author{
Yasuyuki Ishikawa, ${ }^{1,2}$ Yoichiro Horii, ${ }^{1}$ Hideki Tamura, ${ }^{1,2}$ and Sadao Shiosaka ${ }^{1,2}$ \\ ${ }^{1}$ Division of Structural Cell Biology, Nara Institute of Science and Technology, Ikoma, Nara 630-0192, Japan, and ${ }^{2} J a p a n$ Science and Technology Agency, \\ Core Research for Evolutional Science and Technology, Ikoma, Nara 630-0192, Japan
}

\begin{abstract}
Hippocampal early long-term potentiation (LTP) elicited by a weak (one or two) tetanic stimulus normally fades away within 90 min. Late LTP elicited by strong (four) stimuli lasts $>180 \mathrm{~min}$ and requires new protein synthesis to persist. If a strong tetanus is injected once into a synapse, even a weak tetanus injected into another synapse can evoke persistent LTP. It was hypothesized that a synaptic tag enables capture of newly synthesized synaptic molecules. Here, we found two synaptic capture mechanisms for a weakly stimulated synapse to acquire persistency (i.e., neuropsin dependent and independent). The single tetanus evokes a neuropsin-dependent form that follows downstream signaling into integrin/actin signal and L-type voltage-dependent $\mathrm{Ca}^{2+}$ channel (LVDCC) pathway. Additionally, a neuropsin-independent form of synaptic capture is evoked by a stronger (two) tetanus than the former. Both forms converging on LVDCC might serve different associative memories depending on their input strength. Our study strongly supports the hypothesis of synaptic tagging and demonstrates that neuropsin-dependent late associativity is particularly important in nonstressful associative memory.
\end{abstract}

Key words: kallikrein-related peptidase 8; extracellular proteolysis; LTP (long-term potentiation); synaptic capture; synaptic plasticity; integrin

\section{Introduction}

Long-term potentiation (LTP) induced by brief repetitive stimulation brings about activity-dependent and long-lasting enhancement of synaptic efficacy that may explain short-term memory (Bliss and Lømo, 1973; Bliss and Collingridge, 1993; Malenka and Nicoll, 1999). Among the numerous synaptic contacts received by a single neuron, a subset undergoes highly selective modifications when it is repetitively stimulated. Such LTP consists of two temporal phases, early (E-) and late (L-) LTP, occurring independently to establish hyperefficacy in synaptic transmission and regulated by different signaling systems (Krug et al., 1984). Particular temporal and frequency patterns of electric stimuli can evoke E- and L-LTP individually [i.e., weak (one or two trains) stimulation evokes E-LTP, whereas strong (four trains) stimulation evokes L-LTP]. L-LTP requires the activation of a molecular cascade that transfers signals into the nucleus, alters gene expression, and synthesizes new gene products to stabilize LTP in activated synapses (Kandel, 2001). With E-LTP, the synapse does not achieve persistency until the delivery of new proteins, but paradoxically, weak stimulation itself does not induce protein synthesis; therefore, a weakly stimulated synapse produces only a tag (a

Received Sept. 26, 2007; revised Dec. 5, 2007; accepted Dec. 10, 2007

This work was supported in part by a Grant-in-Aid for KAKENHI (17300118) from the Ministry of Education, Culture, Sports, Science, and Technology (Japan).

Correspondence should be addressed to Dr. Sadao Shiosaka, Division of Structural Cell Biology, Nara Institute of Science and Technology, 8916-5, Takayama, Ikoma, Nara 630-0192, Japan. E-mail: sshiosak@bs.naist.jp.

DOI:10.1523/JNEUROSCI.4397-07.2008

Copyright $\odot 2008$ Society for Neuroscience $\quad$ 0270-6474/08/280843-07\$15.00/0 synaptic mark) to capture new proteins generated by other L-LTP-evoked synaptic signaling. Accordingly, accepting and/or addressing mechanisms for the delivery of new proteins from the site of translation were hypothesized (tagging and mailing hypotheses) (Frey and Morris, 1997, 1998; Barco et al., 2002, 2005; Sajikumar and Frey, 2004; Sajikumar et al., 2005; Young and Nguyen, 2005). The candidate molecules relating to the mechanism(s) might be involved in cell-to-cell adhesion, local proteolysis related to synaptic modulation, the formation and degradation of actin networks, the regulation of kinases and ion channels, and local translation (for review, see Martin and Kosik, 2002).

There are possible interactions between the extracellular matrix (ECM) and synaptic membrane modulating LTP-relevant signaling. LTP is interfered with by peptides or antibodies that block the extracellular interactions of integrins and adhesion molecules (Luthl et al., 1994; Ronn et al., 1995; Bahr et al., 1997; Staubli et al., 1998) and that inhibit the activity of ECM proteases: neuropsin [KLK8 (kallikrein-related peptidase 8)] (Komai et al., 2000; Tamura et al., 2006), tissue plasminogen activator (Frey et al., 1996; Huang et al., 1996a; Baranes et al., 1998), and matrix metalloproteases (for review, see Lendeckel and Hooper, 2005; Nagy et al., 2006). The proteases that interact with matrix/adhesion molecules might modify synaptic adhesion to modulate synaptic plasticity without any interference with basal synaptic transmission (Frey et al., 1996; Huang et al., 1996a; Baranes et al., 1998; Komai et al., 2000). We found that neuropsin is a significant modulator of Schaffer-collateral E-LTP and long-term depression acting in a dose-dependent manner (Komai et al., 2000; 
Tamura et al., 2006) and, in unbalanced conditions, causes abnormal plasticity and kindling epileptogenesis (Chen et al., 1995). The modulator function is attributable to (1) cleavage of a presynaptic cell adhesion molecule (CAM)-L1 in an NMDA receptor-dependent manner (Matsumoto-Miyai et al., 2003) and (2) the activity-based changes of neuropsin in postsynaptic signal transduction (Tamura et al., 2006). Considering these findings, neuropsin might be important in the cell biological process for the acquisition of memory depending on input strength. The potentials of extracellular modulation by neuropsin raise a question whether neuropsin induces an interaction between two independent synapses. Therefore, we investigated this issue by using neuropsindeficient mouse and phase-specific stimulation in two separate inputs.

\section{Materials and Methods}

Hippocampal slice preparation. All experiments were conducted with male C57BL/6J mice and neuropsin-deficient mice (age, 4-6 weeks). The production of neuropsin-deficient mice was described by Hirata et al. (2001). Mice were maintained according to the guidelines of the Nara Institute of Science and Technology, and the study was approved by the institutional animal care and use committee. Anesthetized animals were cardiac perfused with ice-cold artificial CSF (ACSF) for deblooding and cooling of

the brain. They were decapitated, and their brains were removed and immersed in ice-cold $\left(4^{\circ} \mathrm{C}\right)$ ACSF bubbled with a mixture of $95 \% \mathrm{O}_{2}$ and $5 \% \mathrm{CO}_{2}$. ACSF consisted of the following (in $\mathrm{mm}$ ): $125 \mathrm{NaCl}, 2.6 \mathrm{KCl}, 1.3$ $\mathrm{MgSO}_{4} 7 \mathrm{H}_{2} \mathrm{O}, 1.24 \mathrm{KH}_{2} \mathrm{PO}_{4}, 26 \mathrm{NaHCO}_{3}, 2.4 \mathrm{CaCl}_{2}$, and 10 D-glucose. The hippocampi were dissected free, and transverse slices ( $400 \mu \mathrm{m}$ thickness) were cut on a slicer (LinearSlicer Pro7; Dosaka, Kyoto, Japan). Slices were allowed to recover at $28^{\circ} \mathrm{C}$ for at least $120 \mathrm{~min}$ before experiments commenced.

Electrophysiology. Extracellular field EPSPs (fEPSPs) were recorded in the stratum radiatum of area CA1 with a glass microelectrode (Narishige, Tokyo, Japan) filled with ACSF (electrical resistances, 2-4 M $\Omega$ ). Extracellular stimulation of the Schaffer-collateral pathway was accomplished with two nickel-chromium (Unique Medical, Tokyo, Japan) bipolar stimulating electrodes (diameter, $40 \mu \mathrm{m}$ ) placed on either side of a single recording electrode in the stratum radiatum. Evoked fEPSPs were amplified (ER-1; Cygnus, Delaware Water Gap, PA), digitized (DigiData 1200 Interface; Molecular Devices, Palo Alto, CA), and analyzed using the LTP program (Anderson and Collingridge, 2001). The test stimulus intensity was adjusted to produce "baseline" fEPSP sizes that were $40 \%$ of the maximal evoked fEPSP slope (SIU-91; Cygnus). Test stimuli were delivered once per minute ( $0.1 \mathrm{~ms}$ stimulus duration) to the Schaffer collaterals with $30 \mathrm{~s}$ separation between stimulations through the two electrodes (stimulating electrodes S0 and S1). To ensure that fEPSPs evoked through each stimulating electrode resulted from the activation of two independent synaptic pathways, we positioned the electrodes so that no paired-pulse facilitation (PPF) was evident after sequential activation of $\mathrm{S} 0$ and S1. The interpathway PPF was assessed at various time intervals ( 50 and $500 \mathrm{~ms}$ ) before baseline acquisition. Basal transmission (inputoutput and PPF) was not significantly different between wild-type (WT) and knock-out (KO) mice (supplemental Fig. 1, available at www. jneurosci.org as supplemental material).

LTP was elicited by delivering the phase-specific potentiation protocol; weak stimulation (single or two tetanic trains; 1 s duration at $100 \mathrm{~Hz}$; intertrain interval, $5 \mathrm{~min}$ ) induced E-LTP; strong stimulation (four tetanic trains) induced L-LTP (Huang and Kandel, 1994; Huang et al., 1996b; Roberson et al., 1996).

Drugs. Anisomycin (Sigma, Tokyo, Japan), a translation inhibitor, was added to ACSF to a final concentration of $20 \mu \mathrm{M}$. GRGDSP (H-Gly-ArgGly-Asp-Ser-Pro-OH; Calbiochem, La Jolla, CA) was added to a final concentration of $100 \mu \mathrm{M}$. Cytochalasin D (Sigma) was added to a final concentration of $0.5 \mu \mathrm{M}$. Nitrendipine (Sigma) was added to a final concentration of $5 \mu \mathrm{M}$. All drugs were bath applied. The final concentration of applied DMSO was $0.01 \%$. At this concentration, baseline fEPSP slopes were not significantly affected (supplemental Fig. 2, available at www.jneurosci.org as supplemental material).

Statistical analysis. The initial fEPSP slope was measured and expressed as a percentage of the averaged baseline. The latter was obtained by averaging $30 \mathrm{~min}$ of fEPSPs measured during baseline acquisition. Data are plotted as the mean \pm SEM. Data sets were analyzed with the TukeyKramer multiple-comparisons test if ANOVA indicated a significant difference between groups ( $p<0.05$; denoted on graphs with an asterisk).

\section{Results}

Previously, using behavioral and in vivo electrophysiological studies, we found that neuropsin KO mice were significantly impaired in hippocampus-dependent behavioral memory as analyzed with the Morris water maze and Y-maze and exhibit a significant decrease in E-LTP induced by a single titanic stimulus (Tamura et al., 2006). To confirm the result and to further analyze stimulation protocols in detail, we used in vitro electrophysiology of hippocampal slice sections, in which one, two, or four high-frequency tetanic stimuli were delivered into the Schaffercollateral pathway (Fig. $1 A-C$ ). One or two stimuli evoked E-LTP significantly lower in $\mathrm{KO}$ (red circles) than WT (black circles) mouse slices (WT vs KO; $1 \times 100 \mathrm{~Hz}, 137 \pm 4 \%, n=8$ vs $119 \pm$ 
A
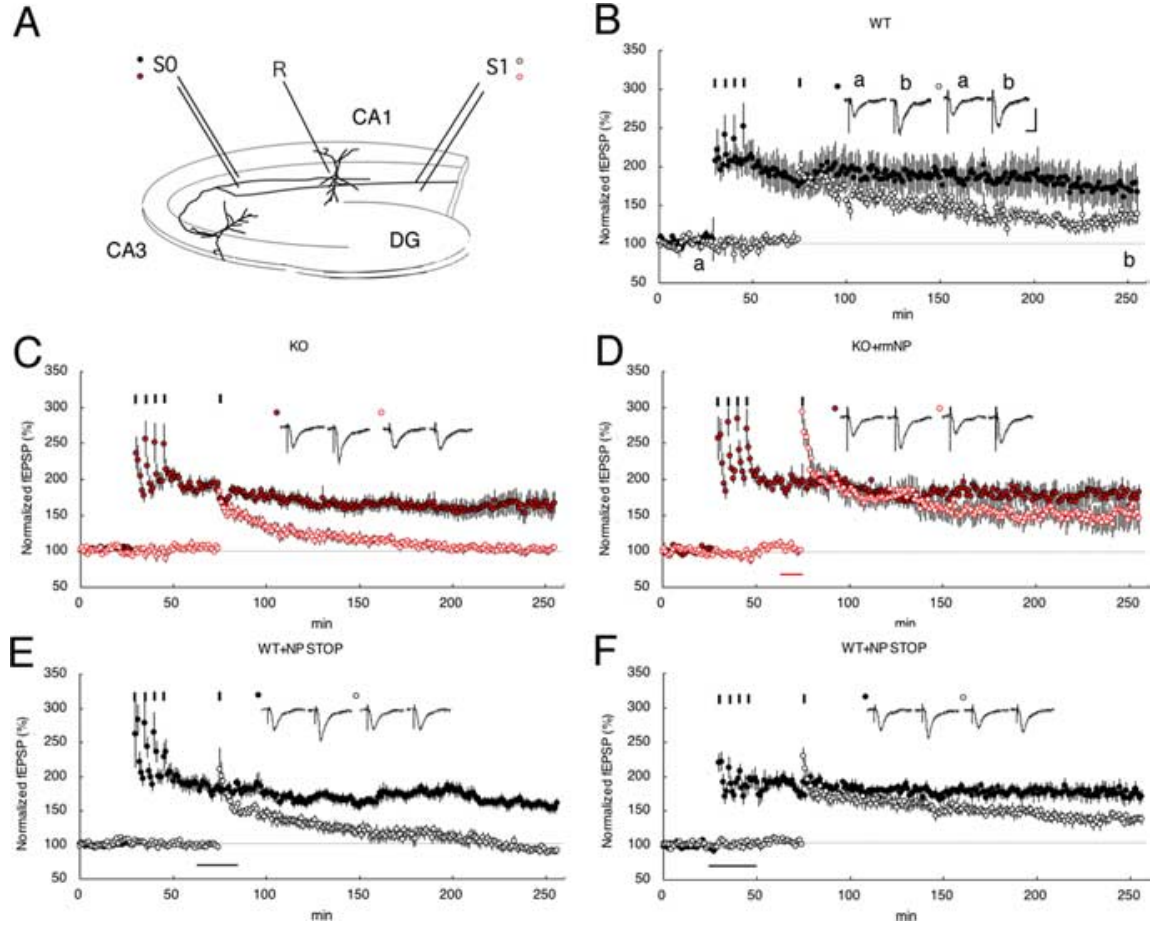

Figure 2. Synaptic late associativity impaired by neuropsin deficiency. $\boldsymbol{A}$, Two independent inputs ( $\mathrm{S} 0$ and S1) into the same population of postsynaptic neurons were alternatively stimulated. R, Recording; DG, dentate gyrus. $\boldsymbol{B}$, A single train of $100 \mathrm{~Hz}$ tetanus to $\mathrm{S} 1$ after four trains of $100 \mathrm{~Hz}$ tetanus in SO (filled circles) expressed stable L-LTP in S1 (open circles). $C$, In contrast, in KO, fEPSP values were impaired in S1 (red open circles) with 180 min posttetanus after four trains of $100 \mathrm{~Hz}$ tetanus in SO (red filled circles). $\boldsymbol{D}, \mathrm{rmNP}$ administration in KO reversed the induction of L-LTP in weak stimulated S1. The red bar indicates rmNP administration. $\boldsymbol{E}, \boldsymbol{F}$, The application of NP STOP was ineffective during strong stimuli (four trains of $100 \mathrm{~Hz}$ tetanus) at $\mathrm{SO}(\boldsymbol{E})$ but effective during a single $100 \mathrm{~Hz}$ tetanus at S1 (F) in WT mice. The black bar indicates NP STOP administration. Calibration: $1 \mathrm{mV}, 10 \mathrm{~ms}$. Inset traces show sample fEPSPs recorded during the baseline (a) period and $180 \mathrm{~min}$ (b) after stimulation at $\mathrm{S1}$. Black short vertical bars indicate tetanic trains.

$4 \%, n=5 ; 2 \times 100 \mathrm{~Hz}, 162 \pm 12 \%, n=6$ vs $124 \pm 11 \%, n=7)$ (Fig. $1 A, B, E$ ). L-LTP was never induced by these weak stimuli both in WT and KO mouse slices (Fig. $1 F$ ) or by weak stimuli on slices with bath application of preactivated recombinant mouse (pro)neuropsin ( $\mathrm{rmNP}$ ) in slices (see below). In contrast, an equal level of E- and L-LTP was found in the strong tetanus $(4 \times$ $100 \mathrm{~Hz}$ ) in slices from WT and $\mathrm{KO}$ mouse slices (WT vs KO; $174 \pm 6 \%, n=6$ vs $175 \pm 21 \%, n=9$ ) (Fig. $1 C, F$ ). Thus, neuropsin might be a potent modulator of E-LTP elicited by a weak (one or two) tetanic stimulus but not of L-LTP elicited by a strong (four) tetanic stimulus.

Because endogenous proneuropsin (inactive) was converted into neuropsin (active) only a few minutes after tetanization, as shown in our previous study (Matsumoto-Miyai et al., 2003), we next checked whether a brief (10 min) bath application of rmNP $(0.3 \mathrm{mU} / \mathrm{ml})$ with a weak tetanic stimulus potentiates E-LTP in $\mathrm{KO}$ as well as in WT mouse slices. The rmNP with a $1 \times 100 \mathrm{~Hz}$ tetanus in $\mathrm{KO}$ mouse slices was successfully reversed into equal levels of E-LTP in WT [KO+rmNP vs WT + rmNP; $150 \pm 25 \%$, $n=5$ vs $158 \pm 8 \%, n=5$ (Fig. $1 D-F$ ); compare with KO, $119 \pm$ $4 \%, n=5$ (Fig. 1A)]. Because a brief bath application of rmNP reversed the altered E-LTP without any potentiation of L-LTP (Fig. 1E,F), we further analyzed the timing for the injection of rmNP and tetanus. Intriguingly, there was an efficacious time window for the brief application of rmNP and the stimulation. The rmNP washed out with ACSF was fully effective at potentiating E-LTP for $30 \mathrm{~min}$, but the effect was eliminated when a single stimulus was injected after $60 \mathrm{~min}$ (data not shown). Thus, tissue slices, once exposed to $\mathrm{rmNP}(<30$ min before the tetanus), might maintain the effect to potentiate E-LTP.

Phase-specific stimulation can evoke E- or L-LTP independently in two separate inputs ( $\mathrm{S} 0$ and $\mathrm{S} 1$ ) for a CA1 pyramidal neuron (Fig. 2A) and was originally used to analyze the associativity of LTPs (Dunwiddie and Lynch, 1978; Frey and Morris, 1997). Using this protocol and KO mouse slices, we analyzed a neuropsin-dependent interaction between two separate synapses. When one pathway was given four tetanic stimuli (S0), S1 with a single tetanic stimulus, which normally produces only E-LTP, resulted in synaptic persistency, representing the association of two synapses (180 min after the tetanus: $136 \pm 6 \%$ at $\mathrm{S} 1, n=7)($ Fig. $2 B)$. This phenomenon is referred to as "late associativity"; however, it completely disappeared in the $\mathrm{KO}$ mouse (180 min after the tetanus: $101 \pm$ $4 \%$ at $\mathrm{S} 1, n=10$ ) (Fig. 2, compare $C, B$ ). This impairment of late associativity was reversed by a brief ( $10 \mathrm{~min}$ ) bath application of rmNP (180 min after the tetanus: $154 \pm 22 \%$ at S1, $n=7$ ) (Fig. 2D); $\mathrm{ANOVA}_{\text {(WT vs KO vs KO+rmNP) }}, F_{(2,10.29)}=$ 11.07, $p<0.003$ ) (see Fig. 5). To further confirm neuropsin-dependent late associativity, we examined it by bath application of NP STOP, a neuropsin-specific inhibitor, into the hippocampal slices from the WT mouse (Fig. 2E,F). Single stimulus in S1 during the application of NP STOP ( $1 \mu \mathrm{g} / \mathrm{ml}, 10 \mathrm{~min})$ completely eliminated the late associativity between $\mathrm{S} 0$ and $\mathrm{S} 1$ synapses (Fig. $2 \mathrm{E}$ ). In contrast, when a strong (four) stimulus in S0 was followed by the application of NP STOP $(1 \mu \mathrm{g} / \mathrm{ml})$, the late associativity between S0 and S1 synapses was not eliminated (Fig. $2 F)\left(\right.$ ANOVA, $F_{(2,12.3)}=23.68$, $p<0.0001)$. Thus, enzymatically active neuropsin might not participate in late associativity between $\mathrm{S} 0$ and $\mathrm{S} 1$ at the $\mathrm{S} 0$ where strong tetanus was injected, but might participate at the S1 site where single tetanus was injected.

Neuropsin is an extracellular protease secreted from axon terminals (Oka et al., 2002b) as a potent endoprotease for fibronectin (Shimizu et al., 1998) and presynaptic CAM-L1 (MatsumotoMiyai et al., 2003). Neuropsin might be important in the process of outside-in signaling of neurons (Tamura et al., 2006); however, the details of molecules involved in this process are not yet known. Therefore, we investigated one of the plausible candidates, integrin/actin polymerization, as a process of outside-in signaling for neuropsin-dependent synaptic late associativity. GRGDSP peptide is known to block the extracellular interactions of adhesion receptors belonging to a subclass of the integrin family, and cytochalasin D is known to prevent actin polymerization, and both drugs had a marked detrimental effect on the induction of E-LTP (Bahr et al., 1997; Kramar et al., 2002; Chan et al., 2003). To investigate whether integrin/actin signaling was involved in late associativity first, we examined by bath application of GRGDSP and cytochalasin D on WT mouse slices. Single tetanus on WT slices normally induced evident L-LTP in S1 $(1 \times 100 \mathrm{~Hz})$ after four tetanus in S0 $(4 \times 100 \mathrm{~Hz})$. Bath application of 
GRGDSP or cytochalasin D, followed by single tetanus in S1, completely impaired late associativity [ $180 \mathrm{~min}$ after single tetanus: WT+GRGDSP, $102 \pm 10 \%$ at S1, $n=7$ (Figs. $3 A, 5$ ); WT + cytochalasin D, $101 \pm 7 \%$ at $\mathrm{S} 1, n=5$ (Figs. $3 B, 5$ )]. Considering the analogous profile of these experiments on impaired late associativity in KO mouse slices, neuropsin-dependent late associativity and integrin/actin signaling might share a common signaling pathway; therefore, we next investigated whether $\mathrm{KO}$ mouse slices supplemented with rmNP and tetanized S1 $(1 \times 100 \mathrm{~Hz})$ after S0 $(4 \times 100 \mathrm{~Hz})$ lose late associativity by the bath application of drugs. Here, if late associativity is not eliminated by drugs, outside-in signaling by neuropsin or integrin/actin is separated. Interestingly, we found that integrin/actin-dependent late associativity shares the neuropsindependent late associativity [180 min after single tetanus: $\mathrm{KO}+\mathrm{rmNP}+\mathrm{GRGDSP}$, $103 \pm 4 \%$ at S1, $n=6$ (Figs. $4 A, 5$ ); $\mathrm{KO}+\mathrm{rmNP}+$ cytochalasin D, $105 \pm 3 \%$ at $\mathrm{S} 1, n=5$ (Fig. $4 B, 5$ )]; therefore, both neuropsin and integrin/actin signaling are part of the pathway leading to late associativity.

Because LTP is known to be regulated by L-type voltage-dependent $\mathrm{Ca}^{2+}$ channel (LVDCC) (Grover and Teyler, 1990; Cavus and Teyler, 1996) activation as well as integrin/actin signaling, we therefore examined whether the LVDCC inhibitor (nitrendipine) prevents late associativity of LTPs in a similar manner as described above. Bath application of nitrendipine followed by a single tetanus treatment with nitrendipine, as shown in Figures $3 C$ and $4 C$, effectively blocked synaptic late associativity both in WT and $\mathrm{KO}$ mouse slices supplemented with rmNP [180 min after tetanus: WT+nitrendipine, $100 \pm 3 \%$ at S1, $n=6$ (Figs. 3C, 5); 180 min after tetanus: $\mathrm{KO}+\mathrm{rmNP}+$ nitrendipine, $97 \pm 3 \%$ at S1, $n=6$ (Fig. 4C, 5)].

These observations using drugs, GRGDSP peptide, actin polymerization inhibitor, and calcium channel blocker suggest that signals from neuropsin-dependent association pass through integrin/actin signaling and also converge into LVDCC signaling. Because both drugs completely canceled the late associativity of $\mathrm{S} 0$ and $\mathrm{S} 1$ provided by rmNP on $\mathrm{KO}$ slices, integrin/actin signaling and LVDCC are located downstream of the neuropsindependent signaling pathway (ANOVA (intergroup of WT),$F_{(4,11.21)}$ $=6.58, p<0.0057 ; \mathrm{ANOVA}_{(\text {intergroup of } \mathrm{KO})}, F_{(5,14.28)}=4.12, p<$ 0.016) (Fig. 5).

Because neuropsin, integrin/actin signaling, and LVDCC might contribute to late associativity, we examined whether per-
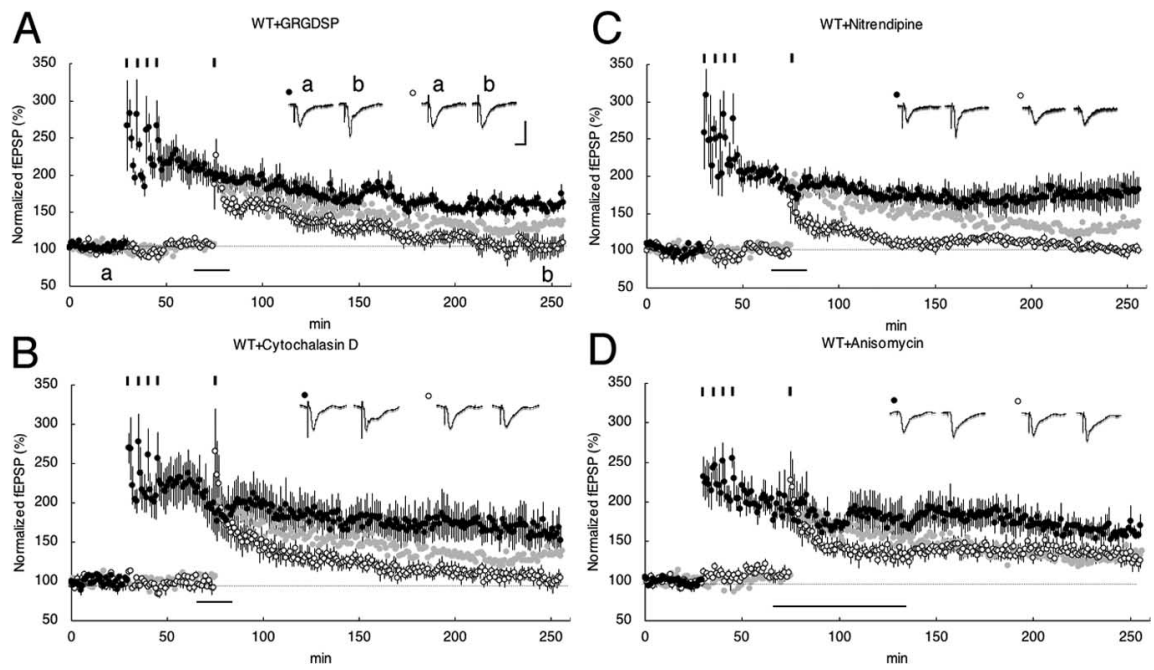

Figure 3. Synaptic late-associativity signaling through integrin/actin into LVDCC. $\boldsymbol{A}$, GRGDSP $(100 \mu \mathrm{m})$ bath applied in WT slices inhibited the expression of stable L-LTP in S1 (open circles) after four trains of $100 \mathrm{~Hz}$ tetanus in S0 (filled circles). $\boldsymbol{B}$, Cytochalasin D $(0.5 \mu \mathrm{m})$ bath applied in WT slices inhibited the expression of stable L-LTP in S1 (open circles) after four trains of 100 Hz tetanus in SO (filled circles). C, Nitrendipine $(5 \mu \mathrm{m})$ bath applied in WT slices inhibited the expression of stable L-LTP in S1 (open circles) after four trains of $100 \mathrm{~Hz}$ tetanus in $\mathrm{SO}$ (filled circles). D, Anisomycin (20 $\mu \mathrm{m}$ ) in WT slices. The black bar indicates periods of drug administration. An fEPSP in the SO pathway is shown by filled circles, and an fEPSP in the S1 pathway is shown by open circles. Calibration: $1 \mathrm{mV}, 10 \mathrm{~ms}$. The $100 \mathrm{~Hz}$-captured LTP in the absence of inhibitors (taken from Fig. $2 \mathrm{~B}$ ) is depicted in light gray for comparison. Inset traces show sample fEPSPs recorded during the baseline (a) period and $180 \mathrm{~min}$ (b) after stimulation at S1. Black short vertical bars indicate tetanic trains, respectively.
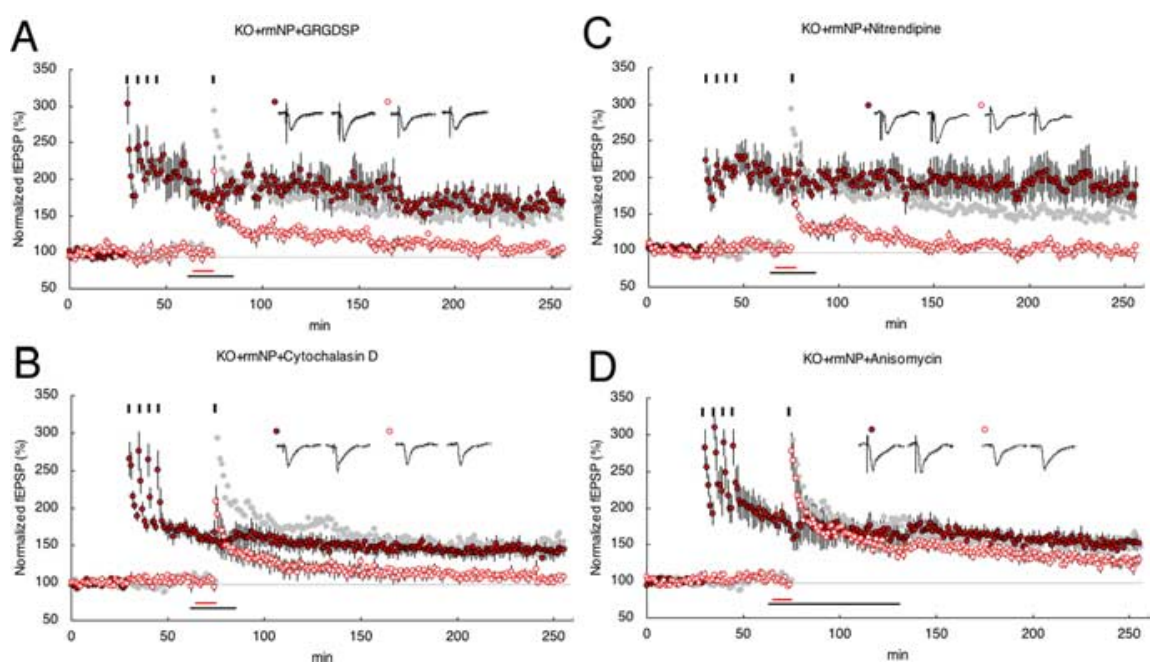

Figure 4. Neuropsin-dependent late associativity and its downstream signaling through integrin/actin into LVDCC. $A$, GRGDSP $(100 \mu \mathrm{M})$ coadministration with rmNP in K0 slices inhibited the expression of stable L-LTP in S1 (red open circles) after four trains of $100 \mathrm{~Hz}$ tetanus in SO (red filled circles). $\boldsymbol{B}$, Cytochalasin D $(0.5 \mu \mathrm{M})$ coadministration with rmNP in KO slices inhibited the expression of stable L-LTP in S1 (red open circles) after four trains of $100 \mathrm{~Hz}$ tetanus in SO (red filled circles). C, Nitrendipine $(5 \mu \mathrm{m})$ coadministration with rmNP in KO slices inhibited the expression of stable L-LTP in S1 (red open circles) after four trains of $100 \mathrm{~Hz}$ tetanus in SO (red filled circles). D, Anisomycin $(20 \mu \mathrm{m})$ rmNP coadministration in KO slices. The black bar indicates periods of drug administration. The red bar indicates periods of rmNP administration. An fEPSP in the SO pathway is shown by filled circles, and an fEPSP in the S1 pathway is shown by open circles. Calibration: $1 \mathrm{mV}, 10 \mathrm{~ms}$. The $100 \mathrm{~Hz}$-captured LTP in the absence of inhibitors (taken from Fig. 2D) is depicted in light gray for comparison. Inset traces show sample fEPSPs recorded during the baseline (a) period and $180 \mathrm{~min}$ (b) after stimulation at $\$ 1$. Black short vertical bars indicate tetanic trains, respectively.

sistency in a single titanic-stimulated S1 synapse is blocked by a protein synthesis inhibitor, anisomycin. After four stimuli were delivered to S0, S1 paired with a single tetanic stimulus in $\mathrm{KO}$ slices in the presence of rmNP did not accompany novel protein synthesis; therefore, in accord with the synaptic tagging hypothesis, it is interpreted that S1 synapses might not induce signaling for protein synthesis but capture synthesized and delivered pro- 


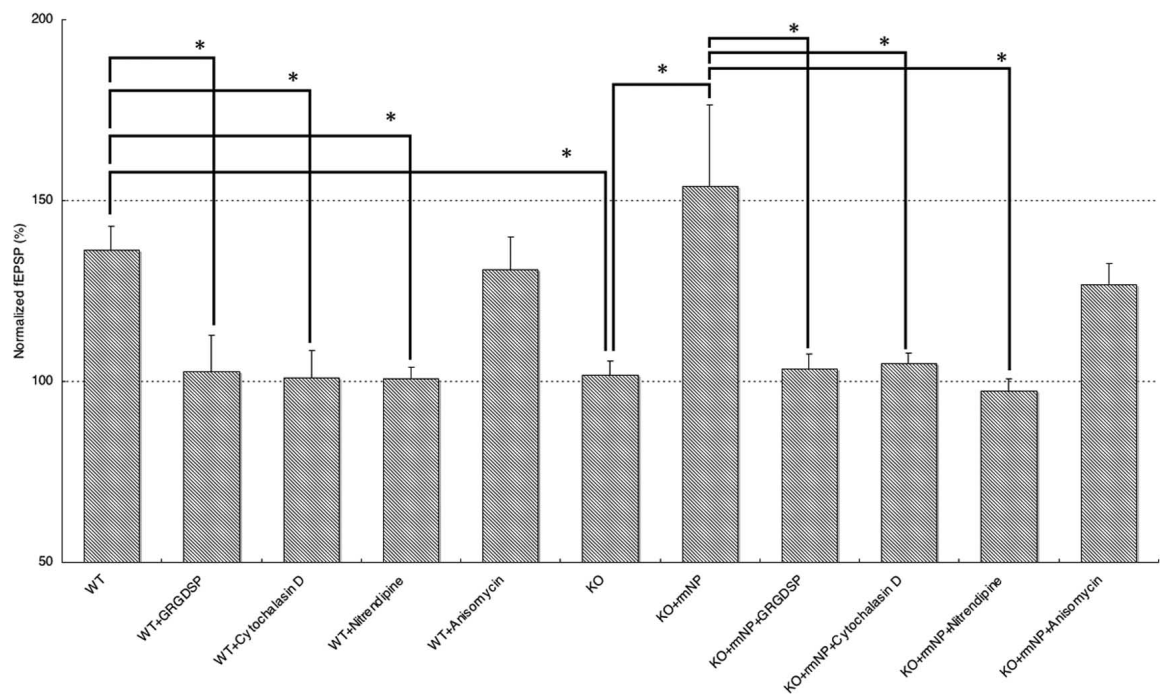

Figure 5. Summary of L-LTP in stimulated S1 synapse after strong stimulation in SO synapse. Mean fEPSP slopes 180 min after weak tetanus were presented. Single tetanus was paired with four trains of $100 \mathrm{~Hz}$ tetanus in SO in WT, WT+ GRGDSP, WT + cytochalasin D, WT + nitrendipine, and WT+ anisomycin. Using KO mice coadministered with rmNP, single tetanus was paired with four trains of $100 \mathrm{~Hz}$ tetanus in $S 0$ (KO, KO+rmNP, KO+rmNP+GRGDSP, KO+rmNP+ cytochalasin D, $\mathrm{KO}+\mathrm{rmNP}+$ nitrendipine, and $\mathrm{KO}+\mathrm{rmNP}+$ anisomycin). $\mathrm{KO}$ mouse slices impaired single tetanus-induced synaptic association, which was reversed with rmNP administration. Late-association LTP was impaired by bath application of GRGDSP, cytochalasin D, and nitrendipine but not by bath application of anisomycin. Asterisks indicate statistical significance $\left({ }^{*} p<0.05\right)$. Error bars indicate SEM.
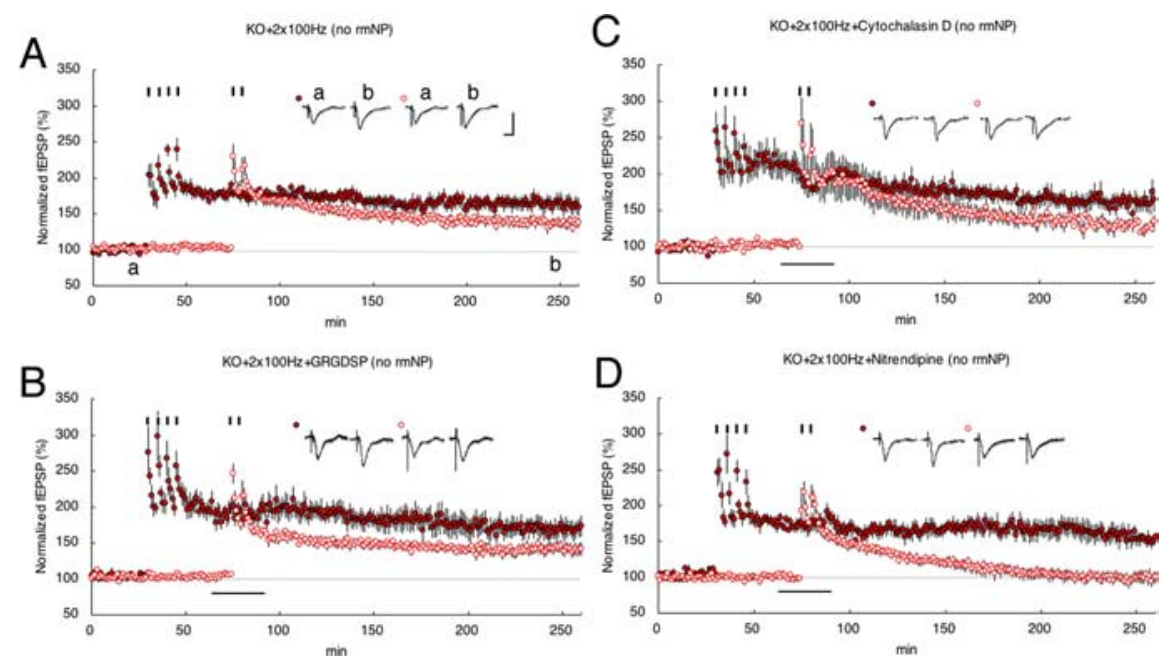

Figure 6. Neuropsin-independent late associativity was blocked by an LVDCC inhibitor. $\boldsymbol{A}$, Two tetanus-induced tagging occurred after four trains of $100 \mathrm{~Hz}$ tetanus in $\mathrm{SO}$ in $\mathrm{KO}$ slices. An fEPSP in $\mathrm{SO}$ to which strong tetanus was applied (red filled circles) evoked stable L-LTP in S1-stimulated two tetanus (red open circles). $\boldsymbol{B}$ - $\boldsymbol{D}$, Late associativity was not blocked by bath application of GRGDSP $(\boldsymbol{B})$ and cytochalasin $\mathrm{D}(\boldsymbol{C})$ but was clearly blocked by nitrendipine $(\boldsymbol{D})$. The black bar indicates the period of drug administration. Calibration: $1 \mathrm{mV}, 10 \mathrm{~ms}$. Inset traces show sample fEPSPs recorded during the baseline (a) period and $180 \mathrm{~min}$ (b) after stimulation at S1. Black short vertical bars indicate tetanic trains, respectively.

teins to S1 synapse [ 180 min after the tetanus: WT+anisomycin, $131 \pm 9 \%$ at $\mathrm{S} 1$ (open circle), $n=5$ (Figs. $3 D, 5$ ); 180 min after the tetanus: $\mathrm{KO}+\mathrm{rmNP}+$ anisomycin, $127 \pm 6 \%$ at $\mathrm{S} 1$ (red open circle), $n=5$ (Figs. 4D, 5) (supplemental Fig. 3, available at www.jneurosci.org as supplemental material)]. The results also show that a weakly stimulated S1 synapse is labeled with tag to capture newly synthesized proteins that are essential for persistency. The tag formation might be controlled by virtue of neuropsin-dependent synaptic association signals.

Stronger $(2 \times 100 \mathrm{~Hz})$ stimuli also evoke E-LTP similar to a single tetanus (Fig. $1 B$ ). When two tetanus were injected in S1 after tetanizing four in S0, late associativity was observed even in $\mathrm{KO}$ mouse slices (180 min after tetanus: $\mathrm{KO}+2 \times 100 \mathrm{~Hz}, 137 \pm 5 \%$ at S1, $n=11$ ) (Fig. $6 A$ ). The results might represent the neuropsin-independent form of association mechanisms; therefore, we further analyzed the RGD peptide, actin polymerization inhibitor, and LVDCC blocker using KO mouse slices without applying rmNP. If drugs impair late associativity produced by two tetanus, neuropsin-independent late associativity also passes through the same signaling. Persistent LTP in KO slices in S1 appeared after two tetanus were not blocked by bath application of GRGDSP $(180$ min after tetanus: $\mathrm{KO}+2 \times 100$ $\mathrm{Hz}+\mathrm{GRGDSP}, 140 \pm 7 \%$ at S1, $n=7$ ) (Fig. $6 B$ ) and cytochalasin D $(180$ min after tetanus: $\mathrm{KO}+2 \times 100$ $\mathrm{Hz}+$ cytochalasin D, $128 \pm 5 \%$ at $\mathrm{S} 1, n=$ 6) (Fig. 6C), and the result shows that signals from neuropsin-independent late associativity are not included in integrin/ actin signaling. However, nitrendipine clearly blocked two tetanus-evoked late associativity (180 min after tetanus: $\mathrm{KO}+2 \times 100 \mathrm{~Hz}+$ nitrendipine, $99 \pm$ $7 \%$ at $\mathrm{S} 1, n=6$; ANOVA, $F_{(3,13.086)}=$ 5.69, $p<0.02$ ) (Fig. 6D); therefore, we concluded that two independent signaling pathways, neuropsin (and integrin/ actin signaling)-dependent and neuropsin-independent late associativity, are present and both systems converge into the same signaling pathway of LVDCC.

\section{Discussion}

Two distinct forms of tagging systems Synaptic tagging is a concept that explains how a weakly stimulated synapse that normally never induces de novo protein synthesis can exhibit persistency in association with a separate strongly stimulated pathway. Because local protein synthesis is not observed in a weakly stimulated synapse, the proteins necessary for persistency should be transported from transcription and translation sites into all synaptic areas. This hypothesis was first introduced by Frey and Morris (1997), who thought that the synapse marked by a weak tetanic stimulus could capture newly synthesized synaptic proteins delivered to the same synapse. Also, a neuropsindependent signaling system that is specific for late associativity is engaged in local synaptic capture. This neuropsin-dependent late associativity is followed by integrin/actin polymerization and LVDCC signaling in which memory signaling presumably crosses over subcellular signaling.

The neuropsin-independent form induced by two high- 
frequency tetanus drives LVDCC. It is known that LVDCCdependent LTP is evoked by high-frequency stimuli (100-200 $\mathrm{Hz}$ ) as NMDA-independent LTP (Grover and Teyler, 1990; Cavus and Teyler, 1996) and is involved in the formation of longerlasting memories, particularly based on stress-driven memory tasks such as food exploration in the radial maze under severe starvation (Borroni et al., 2000) and fear conditioning (Moosmang et al., 2005; McKinney and Murphy, 2006). Neuropsin KO mice were significantly impaired in spatial working memory without any deficit in spatial reference memory in the three-trial Y-maze task under nonstressful conditions of the hippocampus (Tamura et al. 2006) (Y. Ishikawa; Y. Horii, S. Shiosaka, unpublished observation). Spontaneous alternation behavior based on nonstressful or low-stressful Y-maze behavioral tasks is regarded as a measure of spatial working memory. Therefore, the neuropsin-dependent form of tagging might be critical for spatial working memory of nonaversive action of mice. In contrast, the neuropsin-independent form of tagging might be responsible for the stronger stimuli, such as acquisition and retention of spatial reference memory under severe stress-associated conditions, although additional studies are needed to further define this issue.

\section{Neuropsin is related to synaptic morphological change and signaling late associativity}

Perisynaptic proteolysis of the ECM and signal transduction triggered by a complex of neuropsin and serine protease inhibitors may be involved in synaptic morphological changes and synaptogenesis/maturation (Oka et al., 2002a; Nakamura et al., 2006). Matsuzaki et al. (2004) have shown, using two-photon photolysis of caged glutamate at single spines, that glutamate release induces rapid and selective enlargement of the stimulated spine. They argued that small spines are preferential sites for the induction of LTP, whereas larger spines represent physical traces of long-term memory (Matsuzaki et al., 2004). In parallel, neuropsin allows a maturational change of small CAM-L1-immunoreactive boutons, and this step may be important in synaptic plasticity based on activity-dependent structural change (Nakamura et al., 2006). Such dynamic synaptic changes might be involved in the early stages of LTP, including synaptic tagging, and might send outside-in signals to induce the activation of integrin and LVDCC as shown in the present study. The signals might further lead to the activation of c-Src and cAMP-dependent kinase, which are known to be involved in the regulation of LTP (Matsumoto-Miyai et al., 2003; Gui et al., 2006; Isiegas et al., 2006).

In conclusion, the present study revealed neuropsindependent and -independent late associativity. Neuropsindependent late associativity might serve in the acquisition of nonaversive memory (e.g., inquisitive behavior). Consistently, our unpublished analyses of human SNPs revealed a significant association of memory and verbal intelligence quotient with the human neuropsin gene in healthy subjects (Izumi et al., 2008).

\section{References}

Anderson WW, Collingridge GL (2001) The LTP program: a data acquisition program for on-line analysis of long-term potentiation and other synaptic events. J Neurosci Methods 108:71-83.

Bahr BA, Staubli U, Xiao P, Chun D, Ji ZX, Esteban ET, Lynch G (1997) Arg-Gly-Asp-Ser-selective adhesion and the stabilization of long-term potentiation: pharmacological studies and the characterization of a candidate matrix receptor. J Neurosci 17:1320-1329.

Baranes D, Lederfein D, Huang YY, Chen M, Bailey CH, Kandel ER (1998) Tissue plasminogen activator contributes to the late phase of LTP and to synaptic growth in the hippocampal mossy fiber pathway. Neuron 21:813-825.
Barco A, Alarcon JM, Kandel ER (2002) Expression of constitutively active CREB protein facilitates the late phase of long-term potentiation by enhancing synaptic capture. Cell 108:689-703.

Barco A, Patterson S, Alarcon JM, Gromova P, Mata-Roig M, Morozov A, Kandel ER (2005) Gene expression profiling of facilitated L-LTP in VP16-CREB mice reveals that BDNF is critical for the maintenance of LTP and its synaptic capture. Neuron 48:123-137.

Bliss TV, Collingridge GL (1993) A synaptic model of memory: long-term potentiation in the hippocampus. Nature 361:31-39.

Bliss TV, Lømo T (1973) Long-lasting potentiation of synaptic transmission in the dentate area of the anaesthetized rabbit following stimulation of the perforant path. J Physiol (Lond) 232:331-356.

Borroni AM, Fichtenholtz H, Woodside BL, Teyler TJ (2000) Role of voltage-dependent calcium channel long-term potentiation (LTP) and NMDA LTP in spatial memory. J Neurosci 20:9272-9276.

Cavus I, Teyler T (1996) Two forms of long-term potentiation in area CA1 activate different signal transduction cascades. J Neurophysiol 76:3038-3047.

Chan CS, Weeber EJ, Kurup S, Sweatt JD, Davis RL (2003) Integrin requirement for hippocampal synaptic plasticity and spatial memory. J Neurosci 23:7107-7116.

Chen ZL, Yoshida S, Kato K, Momota Y, Suzuki J, Tanaka T, Ito J, Nishino H, Aimoto S, Kiyama H, Shiosaka S (1995) Expression and activitydependent changes of a novel limbic-serine protease gene in the hippocampus. J Neurosci 15:5088-5097.

Dunwiddie T, Lynch G (1978) Long-term potentiation and depression of synaptic responses in the rat hippocampus: localization and frequency dependency. J Physiol (Lond) 276:353-367.

Frey U, Morris RG (1997) Synaptic tagging and long-term potentiation. Nature 385:533-536.

Frey U, Morris RG (1998) Weak before strong: dissociating synaptic tagging and plasticity-factor accounts of late-LTP. Neuropharmacology 37:545-552.

Frey U, Muller M, Kuhl D (1996) A different form of long-lasting potentiation revealed in tissue plasminogen activator mutant mice. J Neurosci 16:2057-2063.

Grover LM, Teyler TJ (1990) Two components of long-term potentiation induced by different patterns of afferent activation. Nature 347:477-479.

Gui P, Wu X, Ling S, Stotz SC, Winkfein RJ, Wilson E, Davis GE, Braun AP, Zamponi GW, Davis MJ (2006) Integrin receptor activation triggers converging regulation of Cav1.2 calcium channels by c-Src and protein kinase A pathways. J Biol Chem 281:14015-14025.

Hirata A, Yoshida S, Inoue N, Matsumoto-Miyai K, Ninomiya A, Taniguchi M, Matsuyama T, Kato K, Iizasa H, Kataoka Y, Yoshida N, Shiosaka S (2001) Abnormalities of synapses and neurons in the hippocampus of neuropsin-deficient mice. Mol Cell Neurosci 17:600-610.

Huang YY, Kandel ER (1994) Recruitment of long-lasting and protein kinase A-dependent long-term potentiation in the CA1 region of hippocampus requires repeated tetanization. Learn Mem 1:74-82.

Huang YY, Bach ME, Lipp HP, Zhuo M, Wolfer DP, Hawkins RD, Schoonjans L, Kandel ER, Godfraind JM, Mulligan R, Collen D, Carmeliet P (1996a) Mice lacking the gene encoding tissue-type plasminogen activator show a selective interference with late-phase long-term potentiation in both Schaffer collateral and mossy fiber pathways. Proc Natl Acad Sci USA 93:8699-8704.

Huang YY, Nguyen PV, Abel T, Kandel ER (1996b) Long-lasting forms of synaptic potentiation in the mammalian hippocampus. Learn Mem 3:74-85.

Isiegas C, Park A, Kandel ER, Abel T (2006) Transgenic inhibition of neuronal protein kinase A activity facilitates fear extinction. J Neurosci 26:12700-12707.

Izumi A, Iijima $\mathrm{Y}$, Noguchi $\mathrm{H}$, Numakawa $\mathrm{T}$, Okada $\mathrm{T}$, Hori $\mathrm{H}$, Kato $\mathrm{T}$, Tatsumi M, Kosuga A, Kamijima K, Asada T, Arima K, Saitoh O, Shiosaka S, Kunugi H (2008) Genetic variations of the neuopsin gene and psychiatric disorders: polymorphism screening and possible association with bipolar disorder and cognitive functions. Neuropsychopharmacology, in press.

Kandel ER (2001) The molecular biology of memory storage: a dialog between genes and synapses. Biosci Rep 21:565-611.

Komai S, Matsuyama T, Matsumoto K, Kato K, Kobayashi M, Imamura K, Yoshida S, Ugawa S, Shiosaka S (2000) Neuropsin regulates an early 
phase of Schaffer-collateral long-term potentiation in the murine hippocampus. Eur J Neurosci 12:1479-1486.

Kramar EA, Bernard JA, Gall CM, Lynch G (2002) Alpha3 integrin receptors contribute to the consolidation of long-term potentiation. Neuroscience 110:29-39.

Krug M, Lossner B, Ott T (1984) Anisomycin blocks the late phase of longterm potentiation in the dentate gyrus of freely moving rats. Brain Res Bull 13:39-42.

Lendeckel U, Hooper N (2005) Proteases in the brain. New York: Springer Science and Business.

Luthl A, Laurent JP, Figurov A, Muller D, Schachner M (1994) Hippocampal long-term potentiation and neural cell adhesion molecules L1 and NCAM. Nature 372:777-779.

Malenka RC, Nicoll RA (1999) Long-term potentiation-a decade of progress? Science 285:1870-1874.

Martin KC, Kosik KS (2002) Synaptic tagging-who's it? Nat Rev Neurosci 3:813-820.

Matsumoto-Miyai K, Ninomiya A, Yamasaki H, Tamura H, Nakamura Y, Shiosaka S (2003) NMDA-dependent proteolysis of presynaptic adhesion molecule L1 in the hippocampus by neuropsin. J Neurosci 23:7727-7736.

Matsuzaki M, Honkura N, Ellis-Davies GC, Kasai H (2004) Structural basis of long-term potentiation in single dendritic spines. Nature 429:761-766.

McKinney BC, Murphy GG (2006) The L-Type voltage-gated calcium channel Cav1.3 mediates consolidation, but not extinction, of contextually conditioned fear in mice. Learn Mem 13:584-589.

Moosmang S, Haider N, Klugbauer N, Adelsberger H, Langwieser N, Muller J, Stiess M, Marais E, Schulla V, Lacinova L, Goebbels S, Nave KA, Storm DR, Hofmann F, Kleppisch T (2005) Role of hippocampal Cav1.2 Ca ${ }^{2+}$ channels in NMDA receptor-independent synaptic plasticity and spatial memory. J Neurosci 25:9883-9892.

Nagy V, Bozdagi O, Matynia A, Balcerzyk M, Okulski P, Dzwonek J, Costa RM, Silva AJ, Kaczmarek L, Huntley GW (2006) Matrix metalloproteinase-9 is required for hippocampal late-phase long-term potentiation and memory. J Neurosci 26:1923-1934.
Nakamura Y, Tamura H, Horinouchi K, Shiosaka S (2006) Role of neurop$\sin$ in formation and maturation of Schaffer-collateral L1camimmunoreactive synaptic boutons. J Cell Sci 119:1341-1349.

Oka T, Akisada M, Okabe A, Sakurai K, Shiosaka S, Kato K (2002a) Extracellular serine protease neuropsin (KLK8) modulates neurite outgrowth and fasciculation of mouse hippocampal neurons in culture. Neurosci Lett 321:141-144.

Oka T, Hakoshima T, Itakura M, Yamamori S, Takahashi M, Hashimoto Y, Shiosaka S, Kato K (2002b) Role of loop structures of neuropsin in the activity of serine protease and regulated secretion. J Biol Chem 277:14724-14730.

Roberson ED, English JD, Sweatt JD (1996) A biochemist's view of longterm potentiation. Learn Mem 3:1-24.

Ronn LC, Bock E, Linnemann D, Jahnsen H (1995) NCAM-antibodies modulate induction of long-term potentiation in rat hippocampal CA1. Brain Res 677:145-151.

Sajikumar S, Frey JU (2004) Late-associativity, synaptic tagging, and the role of dopamine during LTP and LTD. Neurobiol Learn Mem 82:12-25.

Sajikumar S, Navakkode S, Sacktor TC, Frey JU (2005) Synaptic tagging and cross-tagging: the role of protein kinase Mzeta in maintaining long-term potentiation but not long-term depression. J Neurosci 25:5750-5756.

Shimizu C, Yoshida S, Shibata M, Kato K, Momota Y, Matsumoto K, Shiosaka T, Midorikawa R, Kamachi T, Kawabe A, Shiosaka S (1998) Characterization of recombinant and brain neuropsin, a plasticity-related serine protease. J Biol Chem 273:11189-11196.

Staubli U, Chun D, Lynch G (1998) Time-dependent reversal of long-term potentiation by an integrin antagonist. J Neurosci 18:3460-3469.

Tamura H, Ishikawa Y, Hino N, Maeda M, Yoshida S, Kaku S, Shiosaka S (2006) Neuropsin is essential for early processes of memory acquisition and Schaffer collateral long-term potentiation in adult mouse hippocampus in vivo. J Physiol (Lond) 570:541-551.

Young JZ, Nguyen PV (2005) Homosynaptic and heterosynaptic inhibition of synaptic tagging and capture of long-term potentiation by previous synaptic activity. J Neurosci 25:7221-7231. 